\title{
Overexpression of Pto Induces a Salicylate-Independent Cell Death But Inhibits Necrotic Lesions Caused by Salicylate-Deficiency in Tomato Plants
}

\author{
Jianxiong Li, Libo Shan, Jian-Min Zhou, and Xiaoyan Tang \\ Department of Plant Pathology, Kansas State University, Manhattan, KS 66506-5502 U.S.A. \\ Submitted 9 January 2002. Accepted 25 March 2002.
}

\begin{abstract}
Tomato plants overexpressing the disease resistance gene Pto (35S::Pto) exhibit spontaneous cell death, accumulation of salicylic acid (SA), elevated expression of pathogenesis-related genes, and enhanced resistance to a broad range of pathogens. Because salicylate plays an important role in the cell death and defense activation in many lesion mimic mutants, we investigated the interaction of SA-mediated processes and the 35S::Pto-mediated defense pathway by introducing the $n a h G$ transgene that encodes salicylate hydroxylase. Here, we show that $\mathrm{SA}$ is not required for the 35S::Pto-activated microscopic cell death and plays a minor role in defense gene activation and general disease resistance in 35S::Pto plants. In contrast, temperature greatly affects the spontaneous cell death and general resistance in 35S::Pto plants, and high temperature inhibits the cell death. The NahG tomato plants develop spontaneous, unconstrained necrotic lesions on leaves. These lesions also are initiated by the inoculation of a virulent strain of Pseudomonas syringae $\mathrm{pv}$. tomato. However, the NahG-dependent necrotic lesions are inhibited in the NahG/35S::Pto plants. This inhibition is most pronounced under conditions favoring the 35S::Pto-mediated spontaneous cell death development. These results indicate that the signaling pathways activated by Pto overexpression suppress the cellular damage that is caused by SA depletion. We also found that ethylene is dispensable for the $35 \mathrm{~S}::$ Pto-mediated general defense.
\end{abstract}

Plants often react to incompatible pathogens with a rapid killing of the infected cells (hypersensitive response, HR) and an array of defense responses, including a burst of reactive oxygen species, ion flux, cell wall modification, accumulation of phytoalexins, and activation of defense-related genes (HammondKosack and Jones 1996). The mechanism of the HR is unclear, but it is thought to be an active suicide program in plants, which restricts pathogens to the infection site. A pathogen-independent, HR-like cell death can be induced by mutations that presumably mimic the signaling process during infection by incompatible pathogens (Dangl et al. 1996). Lesion mimic mutants have been identified from many plant species including Arabidopsis (Dietrich et al. 1994; Greenberg et al. 1994; Shah et al. 1999), rice (Takahashi et al. 1999; Yin et al. 2000), maize (Walbot et al. 1983), and barley (Wolter et al. 1993). In addition, the lesion mimic phenotype can also be induced by transgenes that appear

Corresponding author: Xiaoyan Tang; E-mail: xtang@plantpath.ksu.edu. to disrupt the normal metabolic processes (Abad et al. 1997; Mittler et al. 1995; Tadege et al. 1998).

The onset of spontaneous lesions in many lesion mimic mutants is regulated by environmental conditions such as light and temperature (Abad et al. 1997; Dietrich et al. 1994; Johal et al. 1994; Mittler et al. 1995; Tadege et al. 1998). Light intensity and day length was reported to affect lesion formation in a number of lesion mimic mutants of maize (Johal et al. 1994) and Arabidopsis (Dietrich et al. 1994). High temperature was shown to suppress lesion formation in tobacco and potato transgenic plants expressing bacterial proton pump and potato transgenic plants expressing pyruvate decarboxylase (Abad et al. 1997; Mittler et al. 1995; Tadege et al. 1998). An environmental effect was also observed in the Arabidopsis $d n d l$ mutant that formed spontaneous lesions only under certain environmental conditions (Clough et al. 2000).

The formation of spontaneous lesions is often associated with SA accumulation, activation of multiple defense-related genes, and elevated general disease resistance (Dangl et al. 1996). In many Arabidopsis lesion mimic mutants, a high level of SA is required for the induction of spontaneous lesions and the activation of defense-related genes and general disease resistance (Bowling et al. 1997; Dietrich et al. 1994; Greenberg 2000; Greenberg et al. 1994; Rate et al. 1999; Shah et al. 1999; Weymann et al. 1995 ). However, in the Arabidopsis $l s d 2$ and $l s d 4$ mutants, SA is dispensable (Hunt et al. 1997), while in the ssi2 mutant, SA is partially required for the induction of spontaneous cell death and defense responses (Shah et al. 2001). In tomato plants, the removal of SA induces spontaneous necrotic lesions but does not significantly impact resistance to Xanthomonas campestris pv. vesicatoria and Cladosporium fulvum (Brading et al. 2000; O'Donnell et al. 2001).

The tomato disease resistance $(R)$ gene Pto encodes a protein kinase that recognizes the bacterial avirulence protein AvrPto and leads to HR and resistance to the bacterial pathogen Pseudomonas syringae pv. tomato (Martin et al. 1993; Tang et al. 1996). Tomato plants overexpressing Pto (35S::Pto) exhibit spontaneous cell death, accumulation of SA, constitutive activation of defense-related genes, and enhanced general resistance (Tang et al. 1999; Xiao et al. 2001). The environmental regulation and the role of SA in the 35S::Pto-mediated defense responses have not been examined. Here, we report that the defense responses activated by $35 \mathrm{~S}::$ Pto are severely inhibited by high temperature. In addition, we found that depletion of SA had only a minor effect on 35S::Pto-mediated 
general resistance, but the necrotic lesions caused by SA depletion were suppressed by $35 \mathrm{~S}::$ Pto.

\section{RESULTS}

\section{S::Pto-mediated general resistance}

is drastically affected by temperature.

Multiple transgenic tomato plants carrying the 35S::Pto transgene showed striking differences when grown in different seasons in the greenhouse. The seasonal effect was studied in detail with MM48, a Money Maker (MM) transgenic line homozygous for the 35S::Pto locus. MM48 plants exhibited massive microscopic cell death when grown during the November through March season, resulting in severe inhibition of plant growth (Fig. 1A). When infected with virulent $P$. syringae pv. tomato $\mathrm{T} 1$ strains, these plants often exhibited approximately 100- to 500-fold more resistance than the nontransgenic plants, as measured by leaf bacterial populations. However, the same transgenic plants showed only minor cell death along the veins and almost normal growth during the June through September season (Fig. 1B). In this season, the MM48 plants showed only approximately 10- to 20-fold more resistance than the nontransgenic plants, as measured by leaf bacterial populations.

The major differences in our greenhouse between the two seasons were day length and temperature: approximately $10 \mathrm{~h}$ light and 16 to $23^{\circ} \mathrm{C}$ during the November through March season and approximately $15 \mathrm{~h}$ light and 27 to $33^{\circ} \mathrm{C}$ during the June through September season. As induction of the spontaneous lesions requires light (Tang et al. 1999), we first determined whether day length affected the spontaneous lesions by adding artificial light to the greenhouse during winter. We found that increasing the photoperiod to 16 to $20 \mathrm{~h}$ November through March did not reduce the spontaneous cell death in 35S::Pto plants. We then tested the influence of temperature on spontaneous lesions by growing the $35 \mathrm{~S}:$ :Pto plants in growth chambers with a 12-h photoperiod (approximately $120 \mu \mathrm{Em}^{-2}$ $\mathrm{s}^{-1}$ of light), $70 \%$ humidity, and a constant temperature of $20^{\circ} \mathrm{C}$ and $30^{\circ} \mathrm{C}$, respectively. Plants grown at $20^{\circ} \mathrm{C}$ showed massive cell death, while plants grown at $30^{\circ} \mathrm{C}$ were almost free of cell death (Fig. 1C, D, and E).

\section{SA plays a minor role in the 35S::Pto-mediated defense.}

The 35S::Pto plants exhibited SA accumulation, microscopic cell death, pathogenesis-related (PR) gene induction, and broad resistance to pathogens (Tang et al. 1999). In many Arabidopsis lesion mimic mutants, these reactions are mediated by a SA-dependent pathway (Rate et al. 1999; Shah et al. 1999; Weymann et al. 1995). To determine whether SA is required for the induction of the various defense responses in 35S::Pto plants, we crossed MM48 with an MM line homozygous for the 35S::nahG transgene (Brading et al. 2000). MM48 plants were also crossed with nontransgenic MM to generate control plants. The SA content was measured in the F1 plants. MM48 $\times$ MM F1 plants accumulated a high level of SA (approximately $27 \mu \mathrm{g}$ of SA per $\mathrm{g}$ of fresh leaves). However, the SA level in the MM48 $\times$ NahG F1 plants was below the detection limit $(<1 \mu \mathrm{g}$ of SA per $\mathrm{g}$ of fresh leaves) of the high-pressure liquid chromatography (HPLC) analysis, similar to that in the parental NahG plants. These results demonstrated that nahG expression effectively blocked the accumulation of SA caused by Pto overexpression.

We then examined whether depletion of SA affected the spontaneous, microscopic cell death in 35S::Pto plants. The leaves of MM48 $\times$ MM and MM48 $\times$ NahG F1 plants were examined with a fluorescence microscope for autofluorescence under UV light, a reliable indicator of spontaneous cell death in 35S::Pto plants. Figure 2 shows cell death in plants grown in March. Both the MM48 $\times$ MM and MM48 $\times$ NahG F1 plants showed a similar level of fluorescence, indicating that depletion of SA did not affect the microscopic cell death caused by Pto overexpression. The two F1 lines also showed similar low levels of cell death in the summer (approximately 27 to $33^{\circ} \mathrm{C}$; data not shown)
A

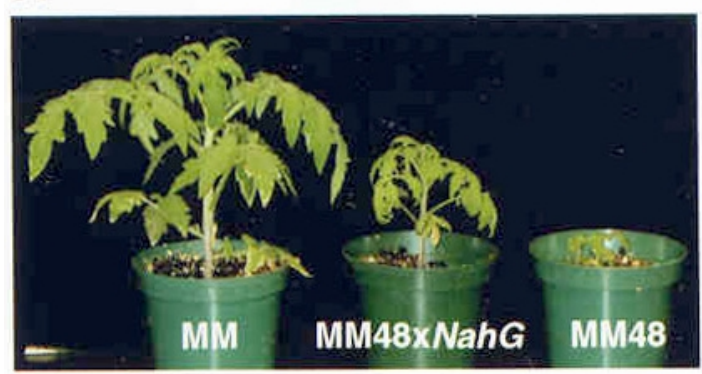

B

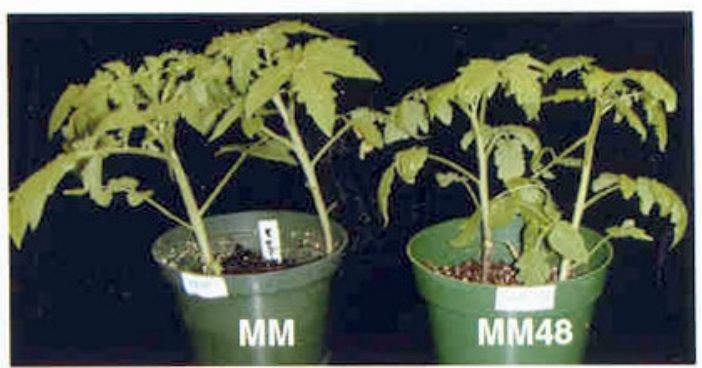

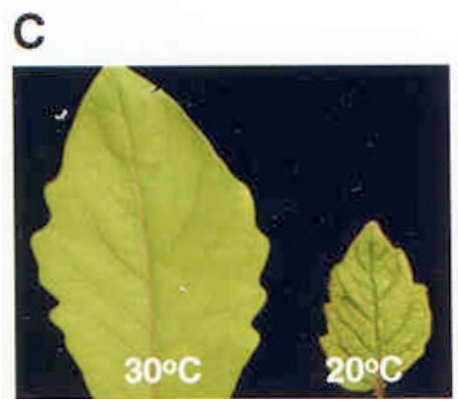
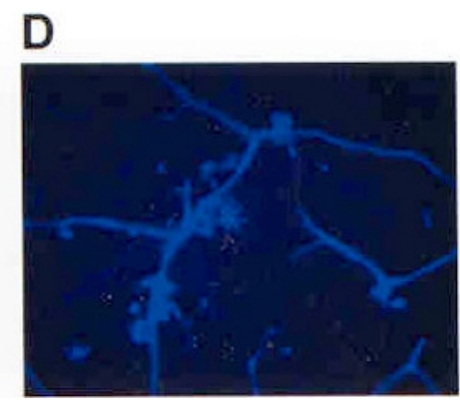

E

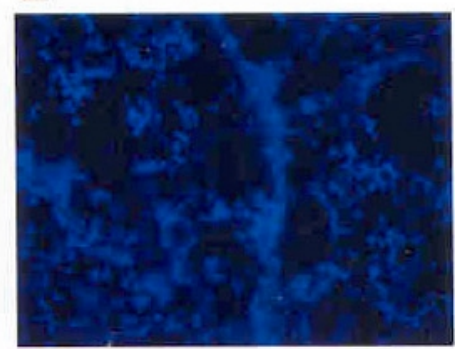

Fig. 1. Low temperature enhances microscopic cell death leading to growth retardation of $35 \mathrm{~S}::$ Pto plants. A, MM, MM48 $\times$ NahG F1, and MM48 plants grown in a greenhouse in February (approximately 16 to $20^{\circ} \mathrm{C}$ ). $\mathbf{B}$, MM and MM48 plants grown in a greenhouse in June (approximately 27 to $30^{\circ} \mathrm{C}$ ). $\mathbf{C}$, Leaves of MM48 plants grown in two growth chambers at 30 and $20^{\circ} \mathrm{C}$, respectively. D, Microscopic cell death of MM48 plants grown in a growth chamber at $30^{\circ} \mathrm{C}$. E, Microscopic cell death of MM48 plants grown in a growth chamber at $20^{\circ} \mathrm{C}$. Cells with strong fluorescence are dead cells. 
To determine how SA depletion affects PR gene expression, we examined the expression of six PR genes in the MM48 $\times$ MM F1, MM48 $\times$ NahG F1, and wild-type MM plants. Figure 3 shows that all the PR genes were expressed at a higher level in plants expressing the $35 \mathrm{~S}:$ :P to gene than in the nontransgenic MM plants. The elevated expression of PR genes, except for $G l u b$, was partially repressed in the presence of the nahG transgene. The repression was more pronounced for Glua than it was for PRla-1, PRlb-1, Chia, and Osmotin (Osm).

We studied how the removal of SA affected the general disease resistance caused by 35S::Pto. F1 plants of MM48 $\times$ NahG and MM48 $\times$ MM were compared for resistance to $P$. syringae pv. tomato $\mathrm{T} 1$ strain, which does not carry the avrPto gene. Figure 4A shows bacterial growth in plants grown in June. Four days after inoculation, reduced bacterial growth was detected in the MM48 $\times$ NahG and MM48 $\times$ MM F1 plants compared with nontransgenic MM plants. However, bacterial numbers in the MM48 $\times$ NahG F1 plants were approximately 4- to 5-fold higher than those in the MM48 $\times$ MM F1 plants, suggesting that SA is partially required for the general resistance caused by 35S::Pto. A similar experiment was conducted in February. Both the MM48 $\times$ MM and MM48 $\times$ NahG F1 plants showed strong resistance, and the bacterial numbers in the MM48 $\times$ NahG F1 plants were slightly higher than those in the MM48 $\times$ MM F1 plants (Fig. 4B).

The NahG plants also were compared with the MM plants for susceptibility to the $\mathrm{T} 1$ infection. In several experiments conducted in different seasons, we observed that the NahG plants supported $<2$-fold more bacterial growth than did the MM plants, again indicating a minimal role of SA in basal resistance to virulent $P$. syringae pv. tomato.

\section{The action of 35S::Pto suppresses necrotic lesions caused by $\mathrm{SA}$ depletion.}

Tomato NahG plants form spontaneous, necrotic lesions on mature leaves and leaf petioles that often result in death of the whole leaf (Fig. 5A and B) (Brading et al. 2000). These lesions are large and morphologically distinct from the 35S::Pto-induced spontaneous cell death that forms bleached, tiny speckles on the adaxial surface of mature leaves. Spontaneous necrotic lesions were also observed in 6- to 7-week-old MM48 $\times$ NahG F1 plants grown in summer, albeit fewer than in plants carrying nahG
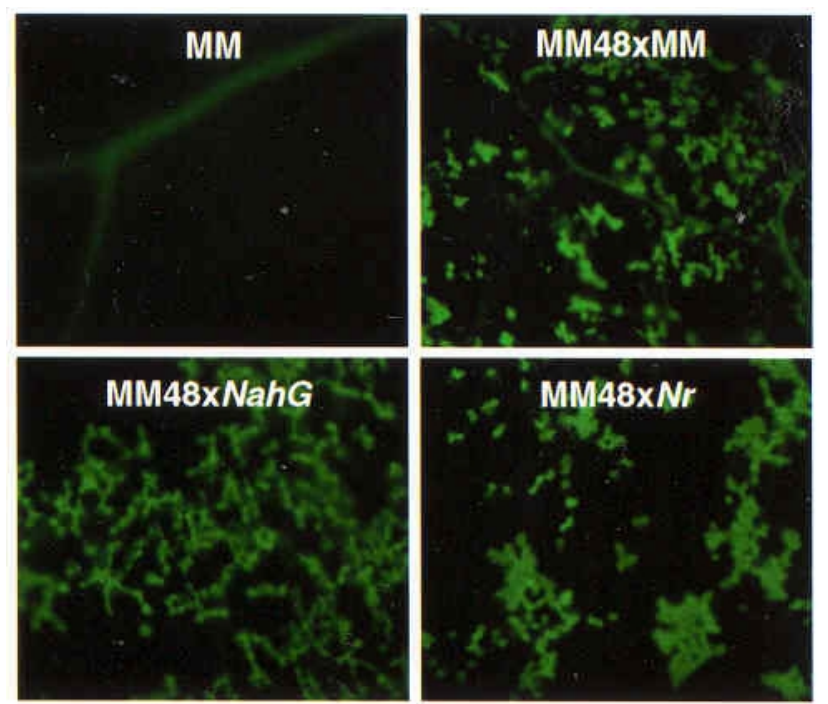

Fig. 2. Spontaneous cell death in 35S::Pto plants was not affected by SA depletion and $\mathrm{Nr}$ mutation. Plants were grown in a greenhouse at 18 to $23^{\circ} \mathrm{C}$. Leaves from MM, MM48 $\times$ MM, MM48 $\times$ NahG, and MM48 $\times$ $\mathrm{Nr}$ are indicated. alone (data not shown). Unlike the 35S::Pto-induced microscopic cell death that was enhanced by low temperature, the large necrotic lesions were completely suppressed in the MM48 $\times$ NahG F1 plants in the winter (Fig. 5A and B). However, the formation of the large necrotic lesions in NahG plants was not affected by temperature or other seasonal changes.

The NahG-dependent necrotic lesions were also triggered by bacterial infection. When inoculated with the virulent $\mathrm{T} 1$ strain of $P$. syringae pv. tomato, both nontransgenic MM plants and NahG transgenic plants developed small necrotic "specks" 3 to 4 days after inoculation (Fig. 5C). The disease lesions showed marginal enlargement in the following week in MM plants. However, the lesions in NahG plants showed uncontrolled expansion after 4 days and eventually engulfed the entire leaf (Fig. 5D and E). Uncontrolled expansion of the disease lesions was also observed in the MM48 $\times$ NahG F1 plants grown in summer (Fig. 5D). The MM48 $\times$ NahG F1 plants grown in winter showed only an average of one to two disease lesions per leaf, which did not expand (Fig. 5E). Interestingly, the uncontrolled lesion expansion in NahG plants and MM48 $\times$ NahG F1 plants was not associated with a further increase of bacterial growth 4 days after inoculation (Fig. 4A), indicating that lesion expansion was not caused by increased susceptibility.

\section{The $\mathrm{Nr}$ mutation does not affect defense responses in 35S::Pto plants.}

Ethylene regulates lesion formation in Arabidopsis acd5 and cpr5 mutants (Clarke et al. 2000; Greenberg et al. 2000), and recent studies indicated that ethylene and SA regulate

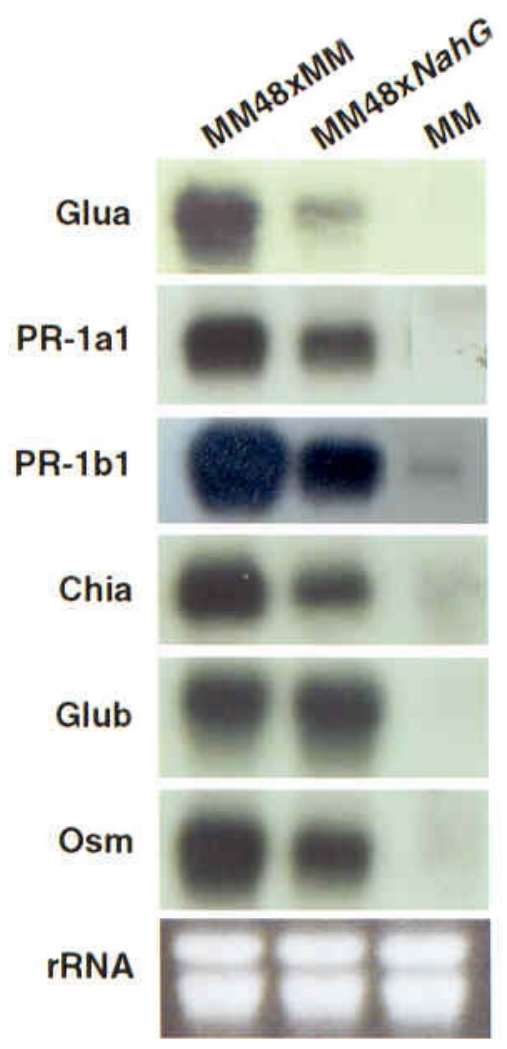

Fig. 3. Salicylic acid depletion partially reduced the pathogenesis-related gene expression in 35S::Pto plants. Total RNA was extracted from fully expanded leaves of MM48 $\times$ MM, MM48 $\times$ NahG, and MM plants grown in a greenhouse at 18 to $23^{\circ} \mathrm{C}$. Total RNA $(10 \mu \mathrm{g})$ was separated in a denaturing agarose gel. Duplicated RNA blots were hybridized with cDNA probes for Glua, PR-1a1, PR-1b1, Chia, Glub, and Osm. Equal loading was verified prior to blotting by visualizing rRNA in the gel stained with ethidium bromide (bottom). 
different sets of defense reactions (Clarke et al., 2000; Penninckx et al. 1996). Because the defense responses in 35S::Pto plants were only partially dependent on SA, we examined whether these responses were regulated by ethylene. The MM48 plant was crossed with the $N r$ mutant. $\mathrm{Nr}$ is a dominant mutation that blocks ethylene signal transduction in tomato (Lanahan et al. 1994). As a control, MM48 was also crossed with the tomato line Pearson (Prsn), the wildtype parent of the $N r$ mutant. The $N r$ mutant shows a number of ethylene-insensitive phenotypes, such as lack of flower senescence and fruit ripening (Lanahan et al. 1994). MM48 $\times$ $\mathrm{Nr}$ F1 plants did not show flower senescence and fruit ripening, indicating disruption of the ethylene signal transduction. MM48 × Prsn F1 plants displayed normal ethylene sensitivity as indicated by normal flower senescence and fruit ripening. The F1 plants of both MM48 $\times N r$ and MM48 $\times$ Prsn exhibited similar cell death (Fig. 2), suggesting that ethylene is not required for induction of spontaneous lesions in tomato plants overexpressing Pto. In addition, PR gene expression was indistinguishable in the MM48 $\times N r$ and MM48 $\times$ Prsn F1 plants (Fig. 6). The F1 plants of MM48 $\times N r$ and MM48 $\times$ Prsn were also examined for resistance to $P$. syringae $p v$. tomato $\mathrm{T} 1$ strain. Both F1 plants supported similarly reduced bacterial growth compared with that in MM $\times$ Prsn F1 (Fig. 7). The MM48 $\times N r$ and MM48 $\times$ Prsn F1 plants developed similar disease symptoms as measured by disease lesion size and number. These data suggest that ethylene is not required for the induction of defense reactions in 35S::Pto plants.

\section{DISCUSSION}

We investigated environmental regulation and the roles of SA and ethylene in the general disease resistance activated by 35S::Pto. We demonstrated that the general defense responses in the 35S::Pto plants were severely inhibited by high temperature. By removing SA and disrupting ethylene signal transduction in 35S::Pto plants, we showed that SA played only a minor role in general defense responses activated by $35 \mathrm{~S}::$ Pto while ethylene was dispensable for this general resistance. In addition, we found that the necrotic lesions associated with $n a h G$ expression were suppressed by Pto-overexpression, indicating an interaction between general resistance and cellular damage caused by SA deficiency.

\section{A}

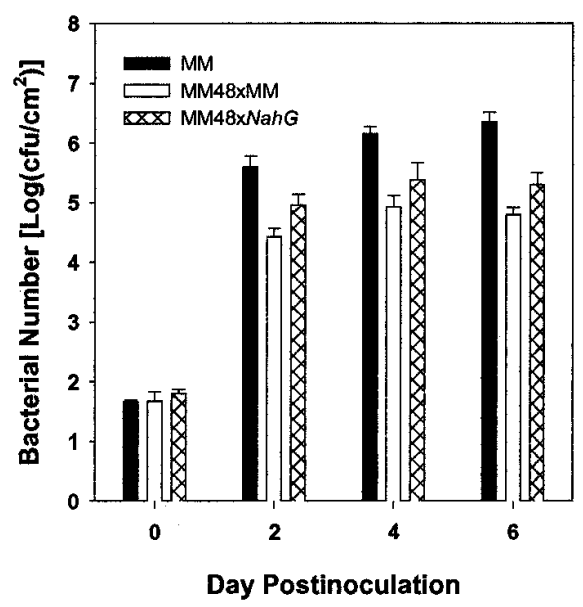

Temperature can modulate both $R$-gene mediated gene-forgene resistance and general defense reactions. For example, it has been reported that high temperature inhibits the $R$-gene mediated resistance to Puccinia coronata in oat, $P$. syringae glycinea in soybean, and Tobacco mosaic virus in tobacco (Dinesh-Kumar et al. 1995; Keen et al. 1981; Zimmer and Schaffer 1961). In addition, high temperature also inhibits spontaneous cell death and general disease resistance in transgenic plants expressing the bacterial proton pump and pyruvate decarboxylase genes (Mittler et al. 1995; Abad et al. 1997; Tadege et al. 1998). In these cases, high temperature may inactivate $R$ gene products, recognition of the $R$ gene products and $a v r$ gene products, or components of the defense signal transduction pathways. We observed that the 35S::Pto-mediated defense responses were severely inhibited at high temperatures. It is yet unclear whether high temperature inactivates Pto kinase or the Pto pathway components. However, it is interesting to note that high temperature was never reported to suppress the Pto-mediated gene-for-gene resistance. If this is indeed the case, it would suggest two possibilities. First, Pto-mediated gene-for-gene resistance and 35S::Pto-mediated general resistance involve different signal transduction components, and the components in the gene-for-gene pathway are insensitive to temperature, while some components required for the 35S::Pto-mediated general resistance are sensitive to high temperature. Second, both Pto-mediated gene-for-gene resistance and 35S::Pto-mediated general resistance are temperature-sensitive, but Pto-mediated gene-for-gene resistance is much stronger than 35S::Pto-mediated general resistance (Tang et al. 1999), and therefore, even though a significant portion of the gene-for-gene resistance is lost at high temperature, the remaining resistance is still sufficient to completely suppress the disease.

Accumulation of SA is observed in lesion mimic mutants with enhanced general disease resistance (Dangl et al. 1996). In many Arabidopsis lesion mimic mutants, high levels of SA are required for lesion formation, induction of PR genes, and enhanced general resistance (Rate et al. 1999; Shah et al. 1999; Vanacker et al. 2001; Weymann et al. 1995). Although tomato plants overexpressing Pto exhibit similar defense characteristics as many Arabidopsis lesion mimic mutants, depletion of SA by the $n a h G$ transgene had no detectable effects on microscopic lesions of the 35S::Pto plants, indicating that SA is not

B

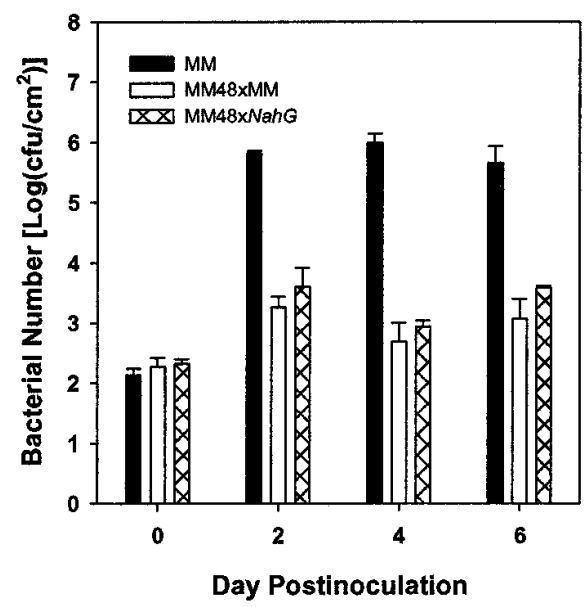

Fig. 4. Salicylic acid depletion slightly reduced the $35 \mathrm{~S}::$ Pto-mediated general resistance. MM, MM48 $\times$ MM, and MM48 $\times$ NahG F1 plants were vacuum-infiltrated with $10^{4} \mathrm{CFU}$ per ml Pseudomonas syringae pv. tomato T1 strain. The growth of the T1 strain on MM, MM48 $\times$ MM, and MM48 $\times$ NahG plants grown in a greenhouse at 27 to $30^{\circ} \mathrm{C}$ (June) and 16 to $20^{\circ} \mathrm{C}$ (February) were measured by grinding two leaf discs in $10 \mathrm{mM} \mathrm{MgCl}{ }_{2}$, plating diluted suspensions on appropriate KB plates, and counting CFU. A, Bacterial growth in June. B, Bacterial growth in February. 
A

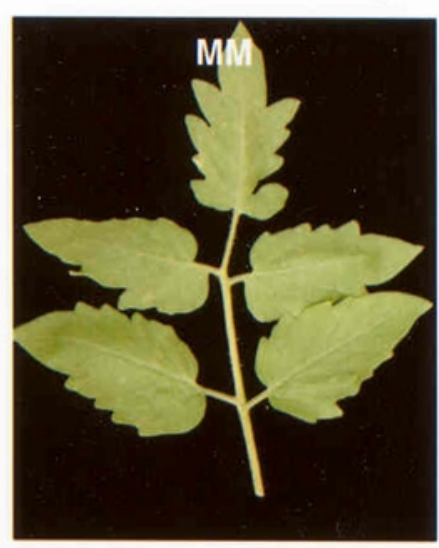

B

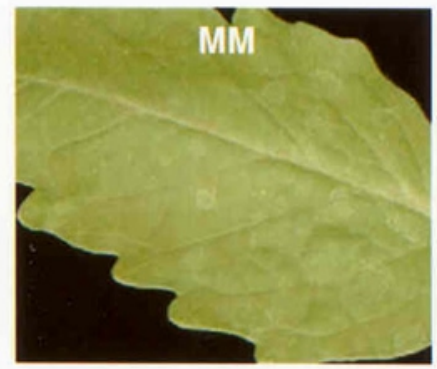

C
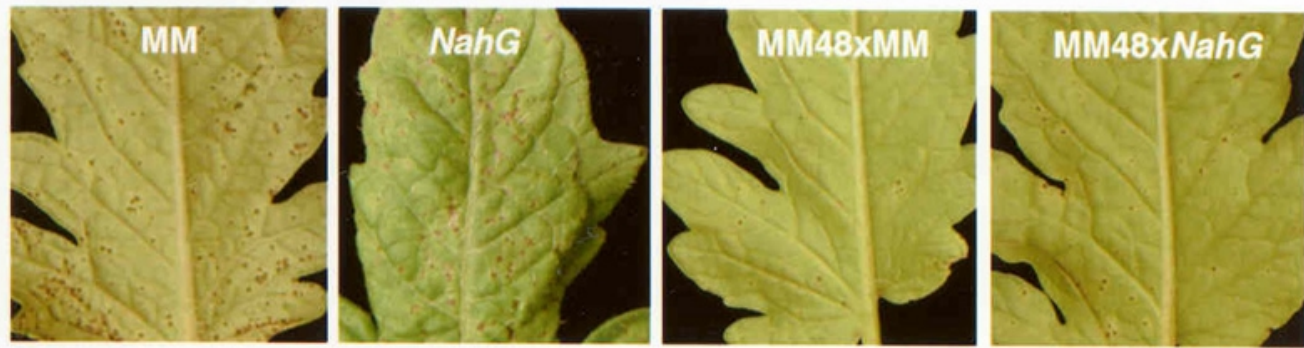

D
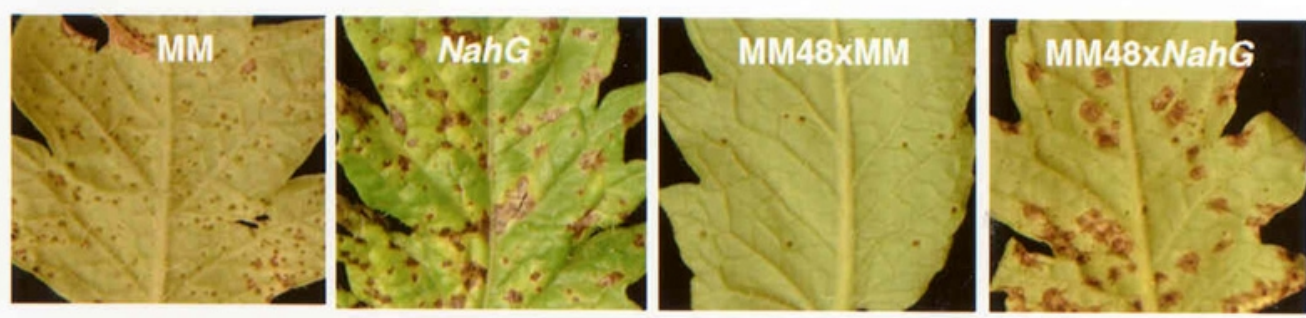

E
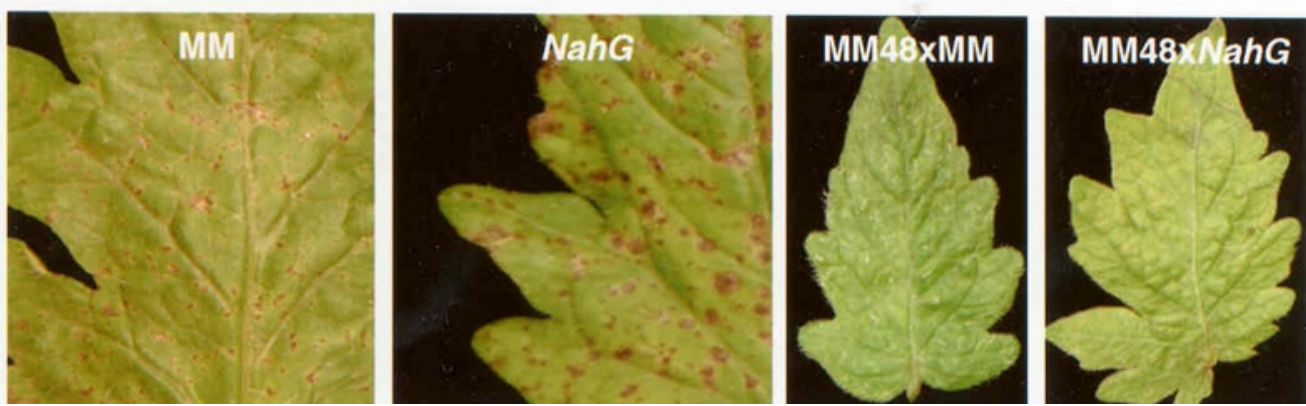

Fig. 5. 35S::Pto suppresses necrotic lesions caused by salicylic acid deficiency. Leaves from the 7-week-old MM, NahG, and MM48 $\times$ NahG F1 plants grown in a greenhouse in January (approximately 16 to $20^{\circ} \mathrm{C}$ ) were photographed to show the spontaneous necrotic lesions on the $\mathbf{A}$, leaf petioles and $\mathbf{B}$, leaves of the NahG plants but not the MM and MM48 $\times$ NahG F1 plants. The MM48 $\times$ NahG leaves in A, and B, are magnified three times. One-monthold MM, NahG, MM48 $\times$ MM F1, and MM48 $\times$ NahG F1 plants grown in a greenhouse in $\mathbf{C}$ and D, June (approximately 27 to $30^{\circ} \mathrm{C}$ ) or $\mathbf{E}$, February (approximately 16 to $20^{\circ} \mathrm{C}$ ) were inoculated with $10^{4} \mathrm{CFU}$ of Pseudomonas syringae pv. tomato $\mathrm{T} 1$ strain per ml. Leaves were photographed at $\mathbf{C}$, 4 days and $\mathbf{D}$ and $\mathbf{E}, 6$ days after inoculation to show disease lesion expansion in the NahG plants and the MM48 $\times$ NahG F1 plants grown in summer and the suppression of necrotic lesions in MM48 $\times$ NahG F1 plants grown in winter. 
necessary for the microscopic cell death caused by $35 \mathrm{~S}::$ Pto. In addition, depletion of SA in the 35S::Pto tomato plants resulted in only a small increase in bacterial growth. The relatively small role of SA in inhibiting the $P$. syringae pv. tomato growth was consistent with the fact that defense-related genes were expressed at high levels in the MM48 $\times$ NahG F1 plants. Ectopic expression of Pto in tomato constitutively activates the expression of at least 70 genes (Tang et al. 1999; Xiao et al. 2001). However, only a small fraction of these genes require SA for their elevated expression in 35S::Pto plants (Xiao et al. 2001). The depletion of SA had only a minor effect on expression of PR-1a1, PR-1b1, Chia, and Osmotin in 35S::Pto plants. The SA-independent defense gene expression may be responsible for the SA-independent resistance to $P$. syringae pv. tomato in 35S::Pto plants.

While depletion of SA in 35S::Pto plants reduced the resistance to $P$. syringae pv. tomato by approximately four- to fivefold, the nahG transgene in plants lacking 35S::Pto had even less impact on the growth of $P$. syringae pv. tomato. In several experiments, we found that the bacterial numbers in NahG plants were less than twofold higher than those in the nontransgenic tomato plants. The insignificant role of SA in resistance to $P$. syringae pv. tomato was consistent with previous reports that SA played only a minimal role in resistance to Xanthomonas campestris pv. vesicatoria (O'Donnell et al. 2001) and Cladosporium fulvum in tomato plants (Brading et al. 2000). The lack of an effect of SA in tomato disease resistance is not likely to be caused by pleiotropic effects of nahG that might have masked SA function, although we cannot completely rule out this possibility. SA-independent disease resistance is not unique to tomato. Arabidopsis plants, in which SA was found to play a critical role in resistance against various pathogens, including $P$. syringae pv. tomato (Delany et al. 1994; Dong 1998), are also able to confer disease resistance in the absence of SA (Hunt et al. 1997; McDowell et al. 2000; Penninckx et al. 1996; Rairdan et al. 2001; Roetschi et al. 2001; Shah et al. 2001). The different requirements for SA by tomato and Arabi-

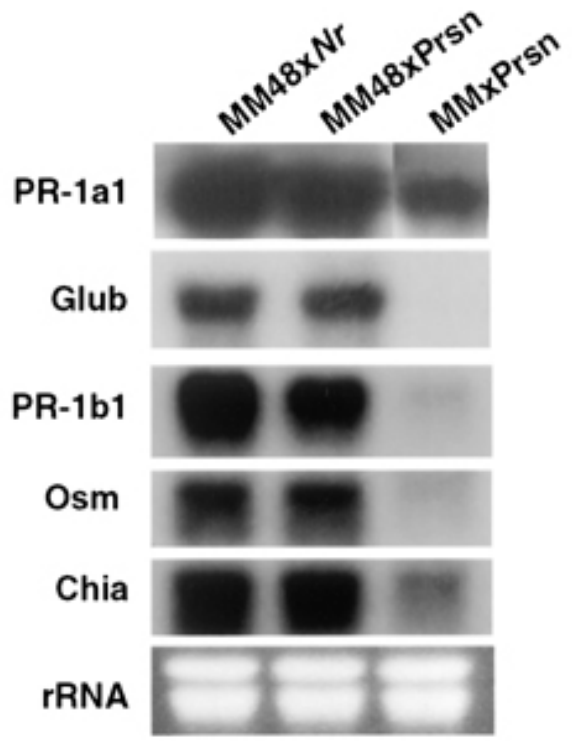

Fig. 6. $\mathrm{Nr}$ mutation does not affect pathogenesis-related gene expression in 35S::Pto plants. Total RNA was extracted from fully expanded leaves of MM48 $\times N r$, MM48 $\times$ Prsn, and MM $\times$ Prsn plants grown in a greenhouse in March (approximately 18 to $23^{\circ} \mathrm{C}$ ). Total RNA $(10 \mu \mathrm{g})$ was loaded in each lane and separated in a denaturing agarose gel. The blots were hybridized with the cDNA probes for $P R-1 a 1$, Glub, PR-1b1, Osm, and Chia. Equal loading was verified by staining the gel with ethidium bromide (bottom) dopsis plants for $P$. syringae pv. tomato resistance suggest that different plant species may employ distinct mechanisms for resistance against the same pathogen.

Tomato plants expressing the $n a h G$ gene form unrestricted necrotic lesions both spontaneously and in response to $P$. syringae pv. tomato infection. The mechanism responsible for the NahG-dependent spontaneous lesions and the uncontrolled disease lesion expansion is not clear, but they appear to be related to a lack of control on cellular damage. Uncontrolled expansion of spontaneous necrotic lesions and disease lesions has been also observed in rice plants expressing $n a h G$ (Yang and Qi 2000). Like tomato, rice plants also contain a high basal level of SA (Brading et al. 2000; Lee et al. 2001). The similar reactions in rice and tomato plants expressing the nahG gene suggest a conserved function of SA in protection against cellular damage, probably because of the antioxidant function of SA. However, the uncontrolled expansion of disease lesions was not observed in the NahG tomato plants infected by $X$. campestris pv. vesicatoria (O'Donnell et al. 2001). How the $X$. campestris pv. vesicatoria infection suppressed the lesion expansion in NahG plants was unclear. Several observations in this study indicate that the uncontained necrotic lesions associated with $n a h G$ expression can be inhibited by a 35S::Pto-mediated function. For example, the MM48 $\times$ NahG F1 plants grown in summer exhibited much less spontaneous necrotic lesion development compared with that on the NahG plants and were completely free of $n a h G$-dependent spontaneous lesions in winter. The stronger suppression in winter is correlated with the more pronounced defense responses conferred by 35S::Pto under lower temperatures. Similarly, uncontrolled disease lesion expansion in the MM48 $\times$ NahG F1 plants was observed only in summer and not in winter. The effect of temperature on $n a h G$-dependent lesions in MM48 $\times$ NahG F1 plants was mediated by $35 \mathrm{~S}::$ Pto, as lesion initiation and expansion in $\mathrm{NahG}$ plants were not affected by temperature. These results suggest that one (or more) of the responses activated by 35S::Pto may act to limit cellular damage caused by SA deficiency. In fact, MM48 plants constitutively accumulate high levels of at least three catalase mRNA species (Xiao et al. 2001). It may be that

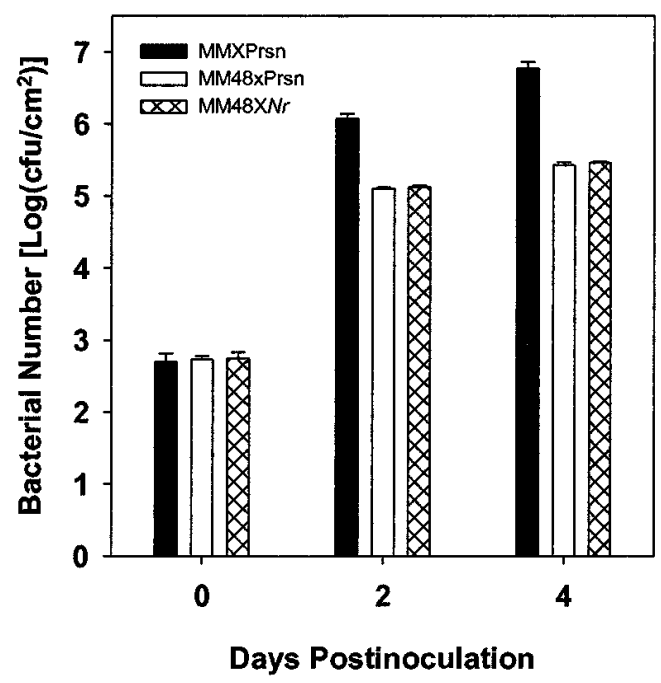

Fig. 7. $\mathrm{Nr}$ mutation does not affect $35 \mathrm{~S}::$ Pto-conferred general resistance. $\mathrm{MM} \times$ Prsn, MM48 $\times$ Prsn, and MM48 $\times N r$ F1 plants grown in a greenhouse in June (approximately 27 to $30^{\circ} \mathrm{C}$ ) were vacuum-infiltrated with $2 \times 10^{4} \mathrm{CFU}$ of Pseudomonas syringae pv. tomato T1 strain per $\mathrm{ml}$. Bacterial growth was measured by grinding two leaf discs in $10 \mathrm{mM}$ $\mathrm{MgCl}_{2}$, plating diluted suspensions on appropriate King's B medium, and counting CFU. Each data point represents the average of three measurements. Error bars indicate standard error. 
increased antioxidant gene expression upon Pto overexpression compensated for the antioxidant function of SA.

The $N r$ mutation did not affect spontaneous cell death or the expression of the PR genes in 35S::Pto plants. As measured by leaf bacterial population, the $N r$ mutation also had no effect on resistance to $P$. syringae pv. tomato in $35 \mathrm{~S}:$ :Pto plants. This is consistent with the report that the growth of $P$. syringae pv. tomato was not affected by $\mathrm{Nr}$ mutation in tomato plants lacking the 35S::Pto transgene (Lund et al. 1998). These results collectively suggest that ethylene does not play a significant role in disease resistance mediated by 35S::Pto. However, the possibility that ethylene plays a role in $35 \mathrm{~S}::$ Pto-mediated resistance can not be completely ruled out, because the $N r$ mutant sometimes shows residual ethylene responses (Lanahan et al. 1994).

\section{MATERIALS AND METHODS}

\section{Plant materials.}

MM48 line was a transgenic Money Maker line containing a single insertion of the 35S::Pto transgene (Tang et al. 1999). The NahG transgenic plants were generated by Brading and associates (2000) and kindly provided by J. Jones. Seeds of the $\mathrm{Nr}$ mutant and Pearson plants were kindly provided by $\mathrm{H}$. Klee. F1 seeds were generated by reciprocal crosses. Tomato plants were grown in a greenhouse or growth chamber. As tomato plants containing the $n a h G$ gene developed uncontrolled lesions when they were older than 6 to 7 weeks, assays were conducted on one-month-old plants.

\section{RNA extraction and RNA gel blot analysis.}

Tomato plants grown in February were used for RNA blot analysis. Well-expanded leaves from one-month-old plants were collected for gene expression analysis. Leaves were immediately frozen in liquid nitrogen after collection, and RNA was isolated as previously described (Tang et al. 1994). Total RNA $(10 \mu \mathrm{g})$ from each sample was loaded on a formaldehydeagarose gel, separated by electrophoresis, transferred to nitrocellulose membrane, and immobilized to the nitrocellulose membrane by UV-crosslinking. cDNA probes for $P R-1 a 1, P R$ 1bl, Chia, Glua, Glub, and Osm genes are as previously described (Tang et al. 1999). All probes were radiolabeled with ${ }^{32} \mathrm{P}-\mathrm{dCTP}$ using a random-primed labeling kit (Amersham, Piscataway, NJ,). RNA gel blot analysis was performed as previously described (Tang et al. 1994).

\section{Histochemistry and microscopy.}

Methods described by Tang and associates (1999) were used for the detection of autofluorescent materials. Briefly, leaves were cleared by boiling in lactophenol and rinsed first in 50\% ethanol and then in water. To visualize autofluorescence, cleared leaves were examined with a UV epifluorescence microscope. Images were obtained using a CCD (charge-coupled device) camera coupled to the microscope.

\section{Measurement of SA.}

SA was extracted as previously described (Bowling et al. 1994) and analyzed with an HPLC coupled with a C18 stainless steel column and a photodiode array detector.

\section{Pathogen infections of tomato leaves.}

P. syringae pv. tomato $\mathrm{T} 1$ strain was inoculated in liquid King's B (KB) medium (Martin et al. 1993) containing $50 \mathrm{mg}$ of rifampicin per 1 and grown overnight. The bacterial cells were washed twice with $10 \mathrm{mM} \mathrm{MgCl}_{2}$ and resuspended in 10 $\mathrm{mM} \mathrm{MgCl} 2$. Bacterial density was determined by absorbance at $600 \mathrm{~nm}$ optical density. Bacteria were diluted to the $2 \times 10^{4}$ CFU per $\mathrm{ml}$ in $10 \mathrm{mM} \mathrm{MgCl}_{2}$ plus $0.04 \%$ Silwet L-77 (Osi,
Danbury, CT, U.S.A.) for inoculation. One-month-old plants were inoculated by vacuum infiltration, and the inoculated plants were kept in a greenhouse. Leaf bacteria were measured by grinding two leaf discs in $10 \mathrm{mM} \mathrm{MgCl}$, plating diluted suspensions on appropriate $\mathrm{KB}$ plates, and counting CFU.

\section{ACKNOWLEDGMENTS}

We thank B. Friebe and P. Zhang for assistance with microscopy and photography. We are grateful to J. Leach, J. Shah, and T. Venkentapa for critically reading the manuscript. This work was supported by a United States Department of Agriculture NRI grant (9802511) to X. T. and a National Science Foundation grant (MCB9808701) to J.-M. Z. The Kansas Agricultural Experimental Station contribution number. is 02-44-J.

\section{LITERATURE CITED}

Abad, M. S., Hakimi, S. M., Kaniewski, W. K., Rommens, C. M. T., Shulaev, V., Lam, E., and Shah, D. M. 1997. Characterization of acquired resistance in lesion mimic transgenic potato expressing bacterio-opsin. Mol. Plant-Microbe Interact. 10:635-645.

Bowling, S. A., Guo, A., Cao, H., Gordon, A. S., Klessig, D. F., and Dong, X. 1994. A mutation in Arabidopsis that leads to constitutive expression of systemic acquired resistance. Plant Cell 6:1845-1857.

Bowling, S. A., Clarke, J. D., Liu, Y. D., Klessig, D. F., and Dong, X 1997. The cpr5 mutant of Arabidopsis expresses both NPR1-dependent and NPR1-independent resistance. Plant Cell 9:1573-1584.

Brading, P. A., Hammond-Kosack, K. E., Parr, A., and Jones, J. D. 2000. Salicylic acid is not required for $C f$-2- and $C f$-9-dependent resistance of tomato to Cladosporium fulvum. Plant J. 23:305-318.

Clarke, J. D., Volko, S. M., Ledford, H., Ausubel, F. M., and Dong, X. 2000. Roles of salicylic acid, jasmonic acid, and ethylene in cpr-induced resistance in Arabidopsis. Plant Cell 12:2175-2190.

Clough, S. J., Fengler, K. A., Yu, I. C., Lippok, B., Smith, R. K., Jr., and Bent, A. F. 2000. The Arabidopsis dnd1 "defense, no death" gene encodes a mutated cyclic nucleotide-gated ion channel. Proc. Natl. Acad. Sci. U.S.A. 97:9323-9328.

Dangl, J. L., Dietrich, R. A., and Richberg, M. H. 1996. Death don't have no mercy: Cell death programs in plant-microbe interactions. Plant Cell 8:1793-1807.

Delaney, T., Uknes, S., Vernooij, B., Friedrich, L., Weymann, K., Negrotto, D., Gaffney, T., Gut-Rella, M., Kessmann, H., Ward, E., and Ryals, J. 1994. A central role of salicylic acid in plant disease resistance. Science 266:1247-1250.

Dietrich, R. A., Delaney, T. P., Uknes, S. J., Ward, E. R., Ryals, J. A., and Dangl, J. L. 1994. Arabidopsis mutants simulating disease resistance response. Cell 77:565-577.

Dinesh-Kumar, S. P., Whitham, S., Choi, D., Hehl, R., Corr, C., and Baker, B. 1995. Transposon tagging of Tobacco mosaic virus resistance gene N: Its possible role in the TMV-N-mediated signal transduction pathway. Proc. Natl. Acad. Sci. U.S.A.. 92:4175-4180.

Dong, X. 1998. SA, JA, ethylene, and disease resistance in plants. Curr. Opin. Plant Biol. 1:316-323.

Greenberg, J. T. 2000. Positive and negative regulation of salicylic aciddependent cell death and pathogen resistance in Arabidopsis $l s d 6$ and ssi1 mutants. Mol. Plant-Microbe Interact. 13:877-881.

Greenberg, J. T., Guo, A., Klessig, D. F., and Ausubel, F. M. 1994. Programmed cell death in plants: A pathogen-triggered response activated coordinately with multiple defense functions. Cell 77:551-63.

Greenberg, J. T., Silverman, F. P., and Liang, H. 2000. Uncoupling salicylic acid-dependent cell death and defense-related responses from disease resistance in the Arabidopsis mutant acd5. Genetics 156:341350 .

Hammond-Kosack, K. E., and Jones, J. D. G. 1996. Resistance gene-dependent plant defense responses. Plant Cell 8:1773-1791.

Hunt, M. D., Delaney, T. P., Dietrich, R. A., Weymann, K. B., Dangl, J. L., and Ryals, J. A. 1997. Salicylate-independent lesion formation in Arabidopsis $l s d$ mutants. Mol. Plant-Microbe Interact. 10:531-536

Johal, G. S., Hulbert, S. H., and Briggs, S. P. 1994. Disease lesion mimics of maize: A model for cell death in plants. Bioessays 17:685-692.

Keen, N. T., Ersek, R., Long, M., Bruegger, B., and Holliday, M. 1981. Inhibition of the hypersensitive reaction of soybean leaves to incompatible Pseudomonas sp by blasticidin S, streptomycin or elevated temperature. Physiol. Plant Pathol. 18:325-337.

Lanahan, M. B., Yen, H. C., Giovannoni, J. J., and Klee, H. J. 1994. The never ripe mutation blocks ethylene perception in tomato. Plant Cell 6:521-530.

Lee, M.-W., Qi, M., and Yang, Y. 2001. A novel jasmonic acid-inducible 
rice $m y b$ gene associates with fungal infection and host cell death Mol. Plant-Microbe Interact. 14:527-535.

Lund, S. T., Stall, R. E., and Klee, H. J. 1998. Ethylene regulates the susceptible response to pathogen infection in tomato. Plant Cell 10:371382

Martin, G. B., Brommonschenkel, S., Chunwongse, J., Frary, A., Ganal, M. W., Spivey, R., Wu, T., Earle, E. D., and Tanksley, S. D. 1993. Map-based cloning of a protein kinase gene conferring disease resistance in tomato. Science 262:1432-1436.

McDowell, J. M., Cuzick, A., Can, C., Beynon, J., Dangl, J. L., and Holub, E. B. 2000. Downy mildew (Peronospora parasitica) resistance genes in Arabidopsis vary in functional requirements for NDR1, EDS1, NPR1 and salicylic acid accumulation. Plant J. 22:523-529.

Mittler, R., Shulaev, V., and Lam, E. 1995. Coordinated activation of programmed cell death and defense mechanisms in transgenic tobacco plants expressing a bacterial proton pump. Plant Cell 7:29-42.

O'Donnell, P. J., Jones, J. B., Antoine, F. R., Ciardi, J., and Klee, H. J. 2001. Ethylene-dependent salicylic acid regulates an expanded cell death response to a plant pathogen. Plant J. 25:315-323.

Penninckx, I. A., Eggermont, K., Terras, F. R., Thomma, B. P., De Samblanx, G. W., Buchala, A., Metraux, J. P., Manners, J. M., and Broekaert, W. F. 1996. Pathogen-induced systemic activation of a plant defensin gene in Arabidopsis follows a salicylic acid-independent pathway. Plant Cell 8:2309-2323.

Rairdan, G. J., Donofrio, N. M., Delaney, T. P. 2001. Salicylic acid and NIM1/NPR1-independent gene induction by incompatible Peronospora parasitica in Arabidopsis. Mol. Plant-Microbe Interact. 14:12351246.

Rate, D. N., Cuence, J. V., Bowman, G. R., Guttman, D. S., and Greenberg, J. T.1999. The gain-of-function Arabidopsis acd6 mutant reveals novel regulation and function of the salicylic acid signaling pathway in controlling cell death, defense, and cell growth. Plant Cell 11:1695-1708.

Roetschi, A., Si-Ammour, A., Belbahri, L., Mauch, F., and Mauch-Mani, B. 2001. Characterization of an Arabidopsis-Phytophthora pathosystem: Resistance requires a functional PAD2 gene and is independent of salicylic acid, ethylene, and jasmonic acid signaling. Plant J. 28:293305

Shah, J., Kachroo, P., and Klessig, D. F. 1999. The Arabidopsis ssi1 mutation restores pathogenesis-related gene expression in npr1 plants and renders defensin gene expression salicylic acid dependent. Plant Cell 11:191-206

Shah, J., Kachroo, P., Nandi, A., and Klessig, D. F. 2001. A recessive mutation in the Arabidopsis SSI2 gene confers SA- and NPR1-independent expression of PR genes and resistance against bacterial and oomy- cete pathogens. Plant J. 25:563-574.

Tadege, M., Bucher, M., Stähli, W., Suter, M., Dupuis, I., and Kuhlemeier C. 1998. Activation of plant defense responses and sugar efflux by expression of pyruvate decarboxylase in potato leaves. Plant J. 16:661671

Takahashi, A., Kawasaki, T., Henmi, K., ShiI, K., Kodama, O., Satoh, H., and Shimamoto, K. 1999. Lesion mimic mutants of rice with alterations in early signaling events of defense. Plant J. 17:535-545.

Tang, X., Gomes, A. M. T. R., Bhatia, A., and Woodson, W. R. 1994. Pistil-specific and ethylene-regulated expression of 1-aminocyclopropane-1-carboxylate oxidase genes in petunia flowers. Plant Cell 6:1227-1239.

Tang, X., Frederick, R. D., Zhou, J., Halterman, D. A., Jia, Y., and Martin, G. B. 1996. Initiation of plant disease resistance by physical interaction of AvrPto and the Pto kinase. Science 274:2060-2063.

Tang, X., Xie, M., Kim, Y. J., Zhou, J., Klessig, D. F., and Martin, G. B. 1999. Overexpression of Pto activates defense responses and confers broad resistance. Plant Cell 11:15-29.

Vanacker, H., Lu, H., Rate, D. N., Greenberg, J. T. 2001. A role for salicylic acid and NPR1 in regulating cell growth in Arabidopsis. Plant J. 28:209-216.

Walbot, V., Hoisington, D. A., and Neuffer, M. G. 1983. Disease lesion mimics in maize. Pages 431-442 in: Genetic Engineering of Plants T. Kosuge, C. P. Meredith, and A. Hollaender, eds. Plenum Publishing, New York.

Weymann, K., Hunt, M., Uknes, S., Neuenschwander, U., Lawton, K., Steiner, H.-Y., and Ryals, J. 1995. Suppression and restoration of lesion formation in Arabidopsis $l s d$ mutants. Plant Cell 7:2013-2022.

Wolter, M., Hollricher, K., Salamini, F., and Schulze-Lefert, P. 1993. The mlo resistance allele to powdery mildew infection in barley trigger a developmentally controlled defense mimic phenotype. Mol. Gen. Genet. 239:122-128.

Xiao, F., Tang, X., and Zhou, J.-M. 2001. Expression of 35S::Pto globally activates defense-related genes in tomato plants. Plant Physiol. 126:1637-1645.

Yang, Y. and Qi, M. 2000. Potential role of salicylic acid in maintaining redox balance of rice plants. Phytopathology 90:S86.

Yin, Z., Chen, J., Zeng, L., Goh, M., Leung, H., Khush, G. S., and Wang, G.-L. 2000. Characterizing rice lesion mimic mutants and identifying a mutant with broad-spectrum resistance to rice blast and bacterial blight. Mol. Plant-Microbe Interact. 13:869-876.

Zimmer, D. E., and Schaffer, J. F. 1961. Relation of temperature to reaction type of Puccinia coronata on certain oat varieties. Phytopathology 51:202-203. 